\title{
Screening of Type 2 Diabetes in the City of Belo Horizonte: Differences between Genders
}

\author{
Braulio Roberto Gonçalves Marinho Couto, Katiussia Brito Porto, \\ Fabiane de Freitas Sales, Deborah Campos Oliveira, Larissa da Silva Pacheco, \\ Lídia Christina Guimarães Pereira, Talita Santos de Almeida, \\ Geiza Francielle Rodrigues de Souza, Mariana Santos Romualdo, \\ Jaqueline Paulino de Souza, Clara Araújo Veloso* \\ Instituto de Ciências Biológicas e da Saúde (ICBS), Centro Universitário de Belo Horizonte, \\ Brasil \\ Email: "claraveloso@yahoo.com
}

Received 17 March 2016; accepted 26 April 2016; published 29 April 2016

Copyright (C) 2016 by authors and Scientific Research Publishing Inc. This work is licensed under the Creative Commons Attribution International License (CC BY). http://creativecommons.org/licenses/by/4.0/

\section{(c) (i) Open Access}

\section{Abstract}

Introduction: Diabetes mellitus is a major public health problem that carries a high social and economic burden. Its diagnosis is unknown in half of individuals who have the disease. The diagnosis of the risk factors should be done in the beginning, since changes in lifestyle and hyperglycemic correction may delay the appearance of the disease and its complications. In this context, screening has been considered an important tool for an early detection of diabetes in asymptomatic adults. Objective: The objective is to track diabetes in people from $\mathrm{BH}$, comparing genders. Patients and methods: People were interviewed with questions concerning the risk factors associated with the development of diabetes. According to the risk factors present, they were classified as non-diabetic [ND], pre-diabetic [PD] or diabetic [DM]. Statistical analyses were performed considering $\mathrm{p} \leq 0.05$ as significant. Results: 1264 individuals participated $(5.5 \% \mathrm{DM}, 6.5 \% \mathrm{PD}, \mathbf{8 8 . 0 \%}$ ND). When grouped, PD and DM males were more prevalent than PD and DM females. Those in the DM group had higher blood pressure, age, glycaemia, number of past smokers, first-degree relatives with diabetes than either PD or ND. Both males and females in DM and PD groups had a higher waist circumference than did either ND males or females. ND men had a higher intake of fried food and smoked more in the past than ND women. Both ND and PD males had higher blood pressure than women from the same groups. Conclusion: Screening for diabetes is very important for an early diagnosis and to avoid future complications in patients. It's possible to infer that women are more conscientious when it comes to taking care of themselves than men.

\footnotetext{
"Corresponding author.

How to cite this paper: Couto, B.R.G.M., Porto, K.B., de Freitas Sales, F., Oliveira, D.C., da Silva Pacheco, L., Pereira, L.C.G., de Almeida, T.S., de Souza, G.F.R., Romualdo, M.S., de Souza, J.P. and Veloso, C.A. (2016) Screening of Type 2 Diabetes in the City of Belo Horizonte: Differences between Genders. Open Journal of Endocrine and Metabolic Diseases, 6, $141-149$. http://dx.doi.org/10.4236/ojemd.2016.64019
} 
Keywords

Diabetes Mellitus, Screening, Gender, Risk Factors

\section{Introduction}

Diabetes mellitus is a major public health problem that carries a high social and economic burden [1]. Type 2 diabetes mellitus [DM2] is the most common form of the disease (representing about $90 \%$ of cases) and it is related to impair the action and production of insulin [2].

The diagnosis of the risk factors should be done in the beginning, since changes in lifestyle and hyperglycemic correction may delay the appearance of the disease and its complications [3] [4]. A diabetes screening campaign done in Brazil in 2001 verified that $50 \%$ of the diagnosed population did not know that they had developed the disease. It is noted that, despite the fact that DM2 has a silent and asymptomatic onset, the life quality for people with diabetes is reduced, with serious complications [2].

The growing prevalence of DM2 is of interest to the public health community. The Diabetes International Federation [IDF] estimated that the number of people with diabetes in the world in 2013 was 387 million, 46\% of which did not have any previous diagnosis. For Brazil, the estimated contingent of 11.9 million cases may reach 19.2 million in 2035 [5]. The prevalence of undiagnosed DM is high. A recent study in six Brazilian capitals, involving individuals between 35 and 74 years of age, found a prevalence of this disease in about 20\%, approximately half of which had never been previously diagnosed [6]. Taking into account these aspects, screening has been considered an important tool for an early detection of diabetes in asymptomatic adults.

Thus, the aim of this study was to screen for diabetes in individuals in the city of Belo Horizonte [BH] and to try to answer the following questions: what is the prevalence of diabetes and pre-diabetes in the city of Belo Horizonte? Is the prevalence of diabetes and pre-diabetes in men different from women? When diabetic, pre-diabetic and non-diabetic groups of people are compared, which risk factors differ in these three groups? In each group of individuals (diabetic, pre-diabetic and non-diabetic) which risk factors differ when men are compared to women?

\section{Patients and Methods}

This study was approved by the Committee of Ethics in Research at Centro Universitario de Belo HorizonteUniBH. The study was performed following the CNS resolution number 466/12. The sample studied corresponds to those individuals who frequent (patients and caregivers) the clinical school of UniBH (various specialties) and others in various points of the city of Belo Horizonte (squares, parks) between August/2012 and December/2014. The selection of the sampling points was made arbitrarily, but covering all regions of the city. Belo Horizonte is located in the state of Minas Gerais, in the southeast region of Brazil. Were included in this study, individuals aged over 18 years old, from both genders, who agreed to sign the informed consent form [ICF]. Individuals under 18 years old, pregnant women and anyone who had not agreed to sign the ICF were excluded.

The sample size was calculated considering an estimation process for an unknown proportion (p) in a population. Considering a margin of error of $2 \%$ and an expected prevalence of $10 \%$ (according to IDF values), it is necessary to have at least 864 patients in order to estimate, with a percentage rate of confidence of $95 \%$, the prevalence of diabetes in the city of Belo Horizonte [7].

The study proposal was presented to the participants who were then asked to answer a questionnaire about their lifestyle habits as well as their medical and family history of diabetes. This questionnaire was standardized for screening programs from the municipality of Belo Horizonte and was applied by previously trained examiners. On the same card, data from blood pressure, waist circumference, weight and height (to calculate the body mass index-BMI) were annotated. For each answer, a score was added. Individuals who numbered more than 9 points were then asked to undergo a capillary blood glucose measurement. The time of the last meal was asked in order to estimate the postprandial time for the execution of the test. People with a fasting glucose level $>126$ $\mathrm{mg} / \mathrm{dL}$ or postprandial glucose level $>200 \mathrm{mg} / \mathrm{dL}$ were considered diabetic. Those considered pre-diabetic were individuals with a fasting glucose level between 100 and $125 \mathrm{mg} / \mathrm{dL}$ or a postprandial glucose level between 140 
and $199 \mathrm{mg} / \mathrm{dL}$. Those considered non-diabetic were individuals with a fasting glucose level $<9 \mathrm{mg} / \mathrm{dL}$ or a postprandial glucose level $<139 \mathrm{mg} / \mathrm{dL}$. These criteria followed the standards of diabetes care [8].

Waist circumference was measured using an inelastic tape measure at the height of the belly button. Weight and height were measured using an anthropometric scale for adults (Filizola-M31). Blood pressure was measured using an aneroid sphygmomanometer with a stethoscope (Premium). Blood glucose was measured using the ACCU-Chek Advantage (Roche Diagnostica Brasil Ltda). Only one device was used for the measurements to avoid conflicting results. These devices were calibrated periodically.

Diabetes and pre-diabetes prevalences were obtained by way of exact estimation and confidence intervals of 95\% for the proportion (C.I. 95\%). Statistical tests of bilateral hypothesis with a significance level of 5\% ( $\alpha \leq$ 0.05 ) were performed when groups of individuals were compared. Categorical factors were evaluated using the Fisher exact test. Quantitative variables were analyzed by analyses of variance [ANOVA] or the non-parametric Kruskal-Wallis test, when necessary. The mean comparisons were performed with the Student t test. All statistical analyses were made using the EpiInfo program (http://www.cdc.gov/epiinfo). It is important to consider that, although the sample used in this study was not obtained by randomization, it may be considered representative of the population of those who are over 15 years of age in the city of Belo Horizonte. 366 people were selected for the sample, which represents the non-discrepant age from the Belo Horizonte population profile according to the 2010 IBGE Census (Figure 1). Although the sample has a higher percentage of women (67\%), compared to the 2010 IBGE Census [9] (54\%), this difference does not prevent the sample from being considered representative of the population of origin.

\section{Results}

\subsection{Population Studied}

1264 individuals participated in the research. 837 people were women and 427 people were men. Independently of gender, the study identified 70 diabetics (a prevalence of 5.5\%-C.I. 95\% $=4.4 \%-7.0 \%$ ), and 82 pre-diabetics (a prevalence of $6.5 \%$-C.I. $95 \%=5.2 \%-8.0 \%$ ).

\subsection{Prevalence of Diabetes, Pre-Diabetes and Non-Diabetes in Each Gender}

Among men, the prevalence of diabetes and pre-diabetes was 6.4\% (C.I. 95\% $=4.3 \%-9.2 \%$ ) and $8.2 \%$ (C.I. $95 \%=5.6 \%-11.3 \%$ ), respectively. Among women, the prevalence of diabetes and pre-diabetes was 5.1\% (C.I. $95 \%=3.8 \%-6.9 \%$ ) and $5.6 \%$ (C.I. $95 \%=4.2 \%-7.5 \%$ ), respectively.

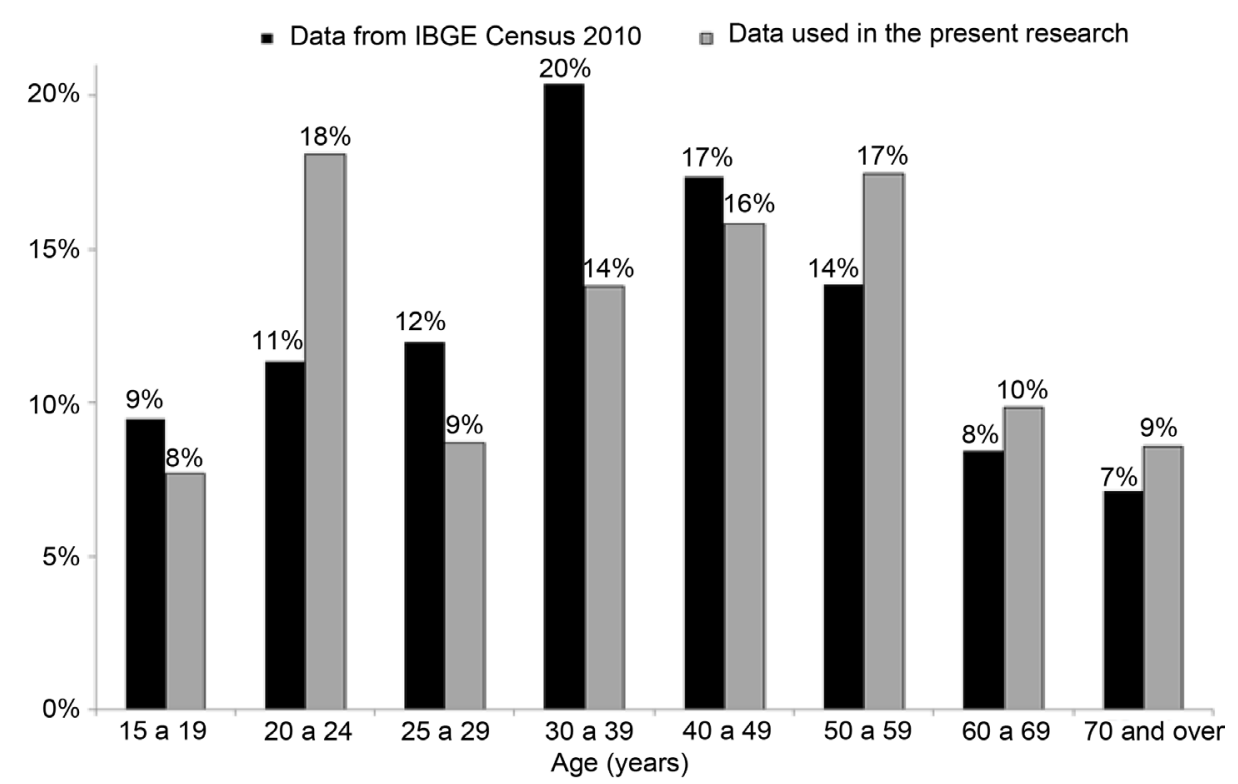

Figure 1. Comparison of demographic data of the IBGE census information of 2010 for the city of Belo Horizonte: the sample used in the survey has representatives from all age groups of the population of Belo Horizonte. 


\subsection{Comparison of the Risk Factors for Diabetes}

There was a significant difference between the genders in diabetic and pre-diabetic populations when they were grouped: $11 \%$ of women were diabetic or pre-diabetic, while this prevalence in men was $14 \%$ (p-value $=0.05$ ).

The results are expressed in tables that demonstrate the comparison of the risk factors for diabetes development in the general population (Table 1) and divided by genders (Tables 2-4).

Table 1. Comparison of risk factors for diabetes development among ND (non-diabetic), PD (pre-diabetic) and DM (diabetes mellitus) groups.

\begin{tabular}{|c|c|c|c|c|}
\hline \multirow{2}{*}{ Characteristics } & \multicolumn{4}{|c|}{ Group } \\
\hline & ND & PD & DM & p-value \\
\hline Physical activity practice (\%) & 39 & 32 & 36 & 0.693 \\
\hline Fry intake (\%) & 45 & 30 & 39 & 0.436 \\
\hline Vegetable frequently intake (\%) & 82 & 56 & 83 & 0.586 \\
\hline Smokers (\%) & 9 & 10 & 16 & 0.133 \\
\hline Past smokers (\%) & 26 & 29 & 46 & $<0.001^{*}$ \\
\hline Have high blood pressure or take medicine to control it (\%) & 27 & 42 & 69 & $<0.001^{* *}$ \\
\hline Have first-degree relatives with diabetes (\%) & 34 & 39 & 64 & $<0.001^{*}$ \\
\hline Have had an alteration of glucose levels in (\%) & 12 & 25 & 61 & $<0.001^{* *}$ \\
\hline Age (years) $(\bar{X} \pm s)$ & $42 \pm 17.9$ & $54 \pm 15.0$ & $58 \pm 12.9$ & $<0.001^{* * *}$ \\
\hline Body mass index (BMI), $\left(\mathrm{kg} / \mathrm{m}^{2}\right)(\bar{X} \pm s)$ & $26 \pm 5.5$ & $30 \pm 5.8$ & $28 \pm 4.5$ & $<0.001^{* *}$ \\
\hline Systolic blood pressure, (mmHg) ( $\bar{X} \pm s)$ & $119 \pm 16$ & $127 \pm 23$ & $131 \pm 16$ & $<0.001^{*}$ \\
\hline Diastolic blood pressure, (mmHg) ( $\bar{X} \pm s)$ & $74 \pm 12$ & $78 \pm 14$ & $81 \pm 12$ & $<0.001^{*}$ \\
\hline Blood glucose, $(\mathrm{mg} / \mathrm{dL})(\bar{X} \pm s)$ & $105 \pm 23$ & $154 \pm 19$ & $218 \pm 95$ & $<0.001^{* *}$ \\
\hline
\end{tabular}

ND: non-diabetic ( $\mathrm{n}=1112)$; PD: pre-diabetic $(\mathrm{n}=82)$; DM: diabetic $(\mathrm{n}=70) ; \quad \bar{X} \pm s \quad$ refers to the mean and standard deviation of the variable. $\left({ }^{*}\right)$ $(\mathrm{PD}=\mathrm{ND}) \neq \mathrm{DM}(\mathrm{p}<0.001),\left(^{* *}\right) \mathrm{PD} \neq \mathrm{ND} \neq \mathrm{DM}(\mathrm{p}<0.001),\left(^{* *}\right)(\mathrm{PD}=\mathrm{DM}) \neq \mathrm{ND}(\mathrm{p}<0.001)$.

Table 2. Comparison between men and women regarding the risk factors for diabetes development: analysis of the group of non-diabetic individuals.

\begin{tabular}{|c|c|c|c|}
\hline \multirow{2}{*}{ Characteristics } & \multicolumn{2}{|c|}{ Gender } & \multirow[b]{2}{*}{ p-value } \\
\hline & Female & Male & \\
\hline Physical activity practice (\%) & 39 & 42 & 0.432 \\
\hline Fry intake (\%) & 42 & 53 & 0.001 \\
\hline Vegetable frequently intake (\%) & 83 & 81 & 0.616 \\
\hline Smokers (\%) & 8 & 12 & 0.102 \\
\hline Past smokers (\%) & 23 & 36 & $<0.001$ \\
\hline Have high blood pressure or take medicine to control it (\%) & 29 & 21 & 0.004 \\
\hline Have first-degree relatives with diabetes (\%) & 36 & 30 & 0.049 \\
\hline Have had an alteration of glucose levels in (\%) & 12 & 14 & 0.198 \\
\hline Age (years) $(\bar{X} \pm s)$ & $42 \pm 18.0$ & $41 \pm 17.9$ & 0.787 \\
\hline Body mass index (BMI), $\left(\mathrm{kg} / \mathrm{m}^{2}\right)(\bar{X} \pm s)$ & $26 \pm 5.8$ & $25 \pm 4.8$ & 0.278 \\
\hline Systolic blood pressure, $(\mathrm{mmHg})(\bar{X} \pm s)$ & $117 \pm 15.6$ & $123 \pm 15.3$ & $<0.001$ \\
\hline Diastolic blood pressure, (mmHg) ( $\bar{X} \pm s)$ & $73 \pm 11.9$ & $77 \pm 11.5$ & $<0.001$ \\
\hline Waist circumference $(\mathrm{cm})(\bar{X} \pm s)$ & $85 \pm 4.6$ & $96 \pm 3.4$ & $<0.001$ \\
\hline Blood glucose, $(\mathrm{mg} / \mathrm{dL})(\bar{X} \pm s)$ & $105 \pm 25.2$ & $106 \pm 16.5$ & 0.723 \\
\hline
\end{tabular}

Sample size: ND = 1112, whereas 747 women (67\%) and 365 men (33\%); $\bar{X} \pm s \quad$ refers to the mean and standard deviation of the variable. 
Table 3. Comparison between men and women regarding the risk factors for diabetes development: analysis of the group of pre-diabetic individuals.

\begin{tabular}{|c|c|c|c|}
\hline \multirow{2}{*}{ Characteristics } & \multicolumn{2}{|c|}{ Gender } & \multirow[b]{2}{*}{ p-value } \\
\hline & Female & Male & \\
\hline Physical activity practice (\%) & 49 & 37 & 0.369 \\
\hline Fry intake (\%) & 30 & 57 & 0.023 \\
\hline Vegetable frequently intake (\%) & 77 & 79 & 0.794 \\
\hline Smokers (\%) & 9 & 21 & 0.188 \\
\hline Past smokers (\%) & 34 & 55 & 0.103 \\
\hline Have high blood pressure or take medicine to control it (\%) & 57 & 57 & 0.843 \\
\hline Have first-degree relatives with diabetes (\%) & 62 & 47 & 0.253 \\
\hline Have had an alteration of glucose levels in (\%) & 14 & 38 & 0.031 \\
\hline Age (years) $(\bar{X} \pm s)$ & $54 \pm 14.5$ & $55 \pm 15.7$ & 0.700 \\
\hline Body mass index (BMI), $\left(\mathrm{kg} / \mathrm{m}^{2}\right)(\bar{X} \pm s)$ & $30 \pm 6.3$ & $29 \pm 5.0$ & 0.333 \\
\hline Systolic blood pressure, (mmHg) ( $\bar{X} \pm s$ ) & $122 \pm 23.8$ & $133 \pm 21.1$ & 0.045 \\
\hline Diastolic blood pressure, (mmHg) ( $\bar{X} \pm s$ ) & $75 \pm 15.5$ & $81 \pm 12.6$ & 0.071 \\
\hline Waist circumference $(\mathrm{cm})(\bar{X} \pm s)$ & $87 \pm 3.9$ & $99 \pm 4.1$ & $<0.001$ \\
\hline Blood glucose, (mg/dL) ( $\bar{X} \pm s)$ & $153 \pm 18.0$ & $155 \pm 21.0$ & 0.576 \\
\hline
\end{tabular}

Sample size: ND = 1112, whereas 747 women (67\%) and 365 men (33\%); $\bar{X} \pm s \quad$ refers to the mean and standard deviation of the variable.

Table 4. Comparison between men and women regarding the risk factors for diabetes development: analysis of the group of diabetic individuals.

\begin{tabular}{|c|c|c|c|}
\hline \multirow{2}{*}{ Characteristics } & \multicolumn{2}{|c|}{ Gender } & \multirow[b]{2}{*}{ p-value } \\
\hline & Female & Male & \\
\hline Physical activity practice (\%) & 41 & 31 & 0.443 \\
\hline Fry intake (\%) & 35 & 44 & 0.458 \\
\hline Vegetable frequently intake (\%) & 88 & 74 & 0.192 \\
\hline Smokers (\%) & 16 & 15 & 1.000 \\
\hline Past smokers (\%) & 40 & 48 & 1.000 \\
\hline Have high blood pressure or take medicine to control it (\%) & 79 & 56 & 0.061 \\
\hline Have first-degree relatives with diabetes (\%) & 63 & 67 & 0.802 \\
\hline Have had an alteration of glucose levels in (\%) & 51 & 77 & 0.043 \\
\hline Age (years) $(\bar{X} \pm s)$ & $57 \pm 15.0$ & $59 \pm 8.9$ & 0.537 \\
\hline Body mass index (BMI), $\left(\mathrm{kg} / \mathrm{m}^{2}\right)(\bar{X} \pm s)$ & $28 \pm 4.6$ & $27 \pm 4.3$ & 0.533 \\
\hline Systolic blood pressure, (mmHg) ( $\bar{X} \pm s)$ & $130 \pm 14.5$ & $133 \pm 18.1$ & 0.401 \\
\hline Diastolic blood pressure, (mmHg) ( $\bar{X} \pm s)$ & $80 \pm 12.5$ & $82 \pm 12.1$ & 0.411 \\
\hline Waist circumference $(\mathrm{cm})(\bar{X} \pm s)$ & $87 \pm 3.3$ & $98 \pm 4.1$ & $<0.001$ \\
\hline Blood glucose, $(\mathrm{mg} / \mathrm{dL})(\bar{X} \pm s)$ & $213 \pm 93.4$ & $225 \pm 98.5$ & 0.641 \\
\hline
\end{tabular}

Sample size: $\mathrm{DM}=70$, whereas 43 women (61\%) and 27 men (39\%); $\bar{X} \pm s$ refers to the mean and standard deviation of the variable.

\section{Discussion}

The prevalence found in this study is slightly lower than that found by the research performed by the Health Ministry of Brazil through the VIGITEL system in 2013 (Surveillance of risk and protective factors for chronic diseases through telephone interviews) (a prevalence of 6.9\% in the Brazilian population) [10] and in another study of self-referred diabetes (a prevalence of 6.2\% in the Brazilian population and 6.5\% in several Brazilian 
capitals, including Belo Horizonte) [6]. This difference may be explained by the methodological differences between the surveys, the year of the survey and the criteria used to indicate the presence of the disease. In the general population studied, $5.1 \%$ were diabetic women; $6.4 \%$ were diabetic men; $5.6 \%$ were pre-diabetic women; $8.2 \%$ were pre-diabetic men; $89.3 \%$ were non-diabetic women and $85.4 \%$ were non-diabetic men. There was no significant difference in the prevalence of diabetics and non-diabetics between genders $(p=0.129)$, when these groups were compared separately. However, when diabetic and pre-diabetic people were grouped, the prevalence of diabetic and pre-diabetic men was higher (14\%) than in women $(11 \% ; p=0.05)$. The literature is controversial in this aspect. Some studies show a higher prevalence of self-referred diabetes in women [11] [12]. However, in a study that used various biochemical measurements for diagnosis, a higher prevalence of diabetes in men was found [6]. Another study concluded that the western dietary pattern, physical inactivity and genetic factors play a fundamental role in the development of diabetes [13]. Furthermore, it was reported that the incidences of diabetes increase with age, obesity, physical inactivity and unhealthy diet [14] [15]. All these risk factors will be discussed below.

Physical inactivity is a major cause for triggering chronic diseases such as diabetes. Booth et al. (2012) [16] speculated that the inactivity was a cause of development of pre-diabetes in people over 60 years old. It is believed that the daily physical exercise may reverse insulin resistance in healthy individuals. In this present research, there was no significant difference $(p>0.100)$ between diabetic, pre-diabetic and non-diabetic groups (Table 1) or between genders (in all situations-Tables 2-4) with respect to the practice of physical activity, which corroborates other studies. Although people know that physical activity is important in the prevention and maintenance of DM2, many people do not exercise [17]. In Brazil, it is estimated that $41 \%$ of the adult population is insufficiently inactive to achieve the health benefits of this activity [18].

With respect to eating habits, there was no significant difference $(p=0.44)$ between diabetic, pre-diabetic and non-diabetic groups related to the ingestion of fried food (Table 1). When genders were compared, it was observed that non-diabetic men (Table 2) and pre-diabetic men (Table 3), eat more fried food than non-diabetic and pre-diabetic women, respectively $(p=0.02)$. There was no significant difference $(p=0.46)$ between genders in diabetic people (Table 4), probably because these individuals should already follow a strict diet. It is well known that diet has the potential to improve glycemic control, reducing the risk of hyperglycemia [19]. With respect to vegetable intake, there was no significant difference between the groups (Table 1 ) or between genders (in all situations-Tables 2-4; $\mathrm{p}>0.100$ ). It has been shown that the consumption of vegetables and fruit by diabetic patients is associated with a decreased risk of developing cardiovascular diseases in this population [20].

Another risk factor for developing diabetes is smoking [21]. A relatively large prospective study showed that quitting smoking reduces the risk of mortality in diabetic patients, but the risk continues increasing a few years after quitting and it is closely related to how long the person has smoked [22]. There was no significant difference $(p=0.13)$ in the number of smokers among the groups (Table 1 ) or genders (in all situations-Tables 2-4), but the percentage of diabetics who have smoked in the past is significantly higher $(p<0.001)$ than non-diabetics or pre-diabetics (Table 1). Between the genders, there was a significant difference $(p=0.10)$ among nondiabetics. Non-diabetic men reported more frequently than non-diabetic women that they had smoked in the past (Table 2). There was no difference between the genders in pre-diabetic (Table 3) or diabetic populations (Table 4) $(p>0.100)$. It is important that people know the risk caused by smoking not only for the development of diabetes, but also for other diseases. Diabetic patients who smoke should initiate programs to stop smoking, even using pharmacological treatments if necessary [21].

Hypertension is a known risk factor for developing diabetes [23]. In this study, 69\% of people with diabetes reported having blood pressure problems (Table 1), which corroborates previous studies that reported that hypertension is present in over $60 \%$ of diabetic patients [23]. There was a significant difference $(p<0.001)$ among ND, PD and DM groups, when asked if they had high blood pressure and, if so, were taking medication to control it. The percentage was lower in NDs, followed by PDs. Diabetics were the group that had the highest percentage of individuals with blood pressure problems. When blood pressure was measured, a significant difference between the groups was found (Table 1). The highest blood pressure (systolic and diastolic) was found in DMs ( $<<0.001)$. There was no significant difference in the blood pressure when PDs and NDs were compared $(p=0.34)$. Comparing genders, there was a significant difference $(p<0.001)$ between non-diabetic women and non-diabetic men with regard to high blood pressure and those taking medicine to control it (Table 2). Women reported having more problems with blood pressure than men $(\mathrm{p}=0.004)$. However, when they had their blood pressure measured, women had lower blood pressure values than men $(\mathrm{p}<0.001)$. This may be due 
to their control of blood pressure with medications, according to the previous question. Among pre-diabetics, there was no significant difference between the genders with respect to having high blood pressure or taking medicines to control it. However, systolic pressure in pre-diabetic men was significantly higher $(\mathrm{p}<0.001)$ than in pre-diabetic women (Table 3). There was no significant difference $(p>0.100)$ between the genders in the diabetic population in any of the above questions (Table 4).

With respect to the questions concerning eating habits, smoking and blood pressure, it was possible to observe a significant difference when comparing women and men. Women eat better, smoke less and have better control of their blood pressure than men do. This data corroborates the literature that shows that women use public health services for routine and preventive tests more often than men [24].

The risk of developing diabetes in people who have relatives with diabetes compared to those who have no relationship to patients increases from 2 to 6 times [25] [26]. This study corroborates the literature, since diabetics have more first degree relatives with diabetes than PDs or NDs $(p<0.001)$ (Table 1). Comparing the genders, it seems that the genetic factors do not affect one sex in the development of the disease more than the other, since there was no significant difference between the genders in PDs (Table 3) or DMs (Table 4) populations $(p>0.100)$ in the percentage of having first-degree relatives with diabetes.

DM2 usually develops in adults, being that age is an important contributor to the development of this disease [8]. Schmidt et al. [6] observed an increased prevalence of diabetes with increasing age, reaching approximately $20 \%$ of the population in age groups of 65-74 year olds and those 75 years old or older. The present study corroborates the literature, since DMs and PDs were significantly older than NDs $(p<0.001)$ (Table 1). There was no significant difference in age between men and women in any of the groups studied ( $>0.100$ ) (Tables 2-4).

One of the biggest risk factors for developing DM2 is obesity. Obese individuals are twenty times more likely to develop diabetes than individuals with normal weight [27]. The results of this study agree with the literature, since the DMs and PDs were found to have higher BMI than the NDs $(\mathrm{p}<0.001)$ (Table 1$)$. There was no difference between the BMI of men and women in any of the groups $(p>0.100)$ (Tables 2-4).

Despite the BMI reporting the degree of overweight and obesity, this measure does not portray the distribution of fat in the body. Since the visceral fat is more metabolically active than the non-visceral, the first is most important in the development of diabetes [28]. Thus, it is important to measure waist circumference as this is able to access the levels of visceral fat [29]. Table 1 does not have the waist circumference data because, in this table, men and women are clustered and the measure of waist circumference differs between the sexes. Tables 2-4 show a significant difference in waist circumference between the genders $(\mathrm{p}<0.001)$, which was to be expected as the value for the determination of it is different between the sexes. When the waist circumference is compared between the ND, PD and DM groups, in individuals of the same gender, it is observed that, among women, the NDs have a lower waist circumference than the PDs and DMs $(\mathrm{p}<0.001)$. There is no difference between PD and DM females. The same is true among men, showing that waist circumference is an important predisposing factor of the disease, in agreement with previous findings [29] [30].

As glucose is the characteristic used to separate groups of NDs, PDs and DMs, it was expected that there were significant differences between the groups (Table 1). Tables 2-4 demonstrate that there was no difference between the blood glucose of men and women in the groups studied ( $p>0.100)$, which is consistent with the reference values for diabetes. These values are the same for both sexes [8].

\section{Conclusion}

The combined prevalence of diabetes and pre-diabetes in men is greater than that found in women. Diabetics are older, with a higher BMI, a higher waist circumference and higher blood pressure, and they smoke more in the past and have more first-degree relatives with the disease than non-diabetics. Between the genders, it is observed that women eat better, smoke less and control their blood pressure better than men. The complex interaction between risk factors for the development of diabetes demonstrates the need for the monitoring of this chronic disease by the health services community. Screening of diabetes is important for an early diagnosis and to avoid future complications to the patients.

\section{Conflicts of Interest}

The authors declare no conflicts of interest. 


\section{Acknowledgements}

To UniBH, for financial support, and to the entire team that participated in applying the questionnaires and tabulating the data.

\section{References}

[1] Narayan, K.M.V., Gregg, E.W., Fagot-Campagna, A., et al. (2000) Diabetes-A Common, Growing, Serious, Costly, and Potentially Preventable Public Health Problem. Diabetes Research and Clinical Practice, 50, S77-S84. http://dx.doi.org/10.1016/S0168-8227(00)00183-2

[2] Mazzini, M.C.R., et al. (2013) Rastreamento do risco de desenvolvimento de diabetes mellitus em pais de estudantes de uma escola privada na cidade de Jundiaí, São Paulo. Revista da Associação Médica Brasileira, 59, 136-142. http://dx.doi.org/10.1016/j.ramb.2012.09.002

[3] Knowler, W.C., et al. (2002) Reduction in the Incidence of Type 2 Diabetes with Lifestyle Intervention or Metformin. The New England Journal of Medicine, 346, 393-403. http://dx.doi.org/10.1056/NEJMoa012512

[4] Shankaracharya, Odedra, D., Mallick, M., et al. (2012) Java-Based Diabetes Type 2 Prediction Tool for Better Diagnosis. Diabetes Technology \& Therapeutics, 14, 251-256. http://dx.doi.org/10.1089/dia.2011.0202

[5] International Diabetes Federation (2014) IDF Diabetes Atlas. 6th Edition, Brussels, Belgium.

[6] Schmidt, M.I., Hoffmann, J.F., de Fátima Sander Diniz, M., et al. (2014) High Prevalence of Diabetes and Intermediate Hyperglycemia-The Brazilian Longitudinal Study of Adult Health (ELSA-Brasil). Diabetology \& Metabolic Syndrome, 6, 123. http://dx.doi.org/10.1186/1758-5996-6-123

[7] Hulley, S., et al. (2006) Delineando a pesquisa clínica: uma abordagem epidemiológica. 2nd Edition, ARTMED Editora, Porto Alegre.

[8] American Diabetes Association (2014) Standards of Medical Care in Diabetes_-2014. Diabetes Care, 37, S14-S80. http://dx.doi.org/10.2337/dc14-S014

[9] IBGE. Censo Demográfico 2010 (2011) Características da população e dos domicílios: Resultados do universo. IBGE, Rio de Janeiro, 151.

[10] Secretaria de Vigilância em Saúde (2013) Vigilância de fatores de risco e proteção para doenças crônicas por inquérito telefônico, B. Ministério da Saúde, Brasília.

[11] de Freitas, L.R.S. and Garcia, L.P. (2012) Evolução da prevalência do diabetes e deste associado à hipertensão arterial no Brasil: Análise da Pesquisa Nacional por Amostra de Domicílios, 1998, 2003 e 2008. Epidemiologia e Serviços de Saúde, 21, 7-19. http://dx.doi.org/10.5123/S1679-49742012000100002

[12] Schmidt, M.I., Duncan, B.B., Hoffmann, J.F., de Moura, L., Malta, D.C. and Carvalho, R.M. (2009) Prevalence of Diabetes and Hypertension Based on Self-Reported Morbidity Survey, Brazil, 2006. Revista de Saúde Pública, 43, 74-82. http://dx.doi.org/10.1590/S0034-89102009000900010

[13] Garcia-Dominic, O., et al. (2014) Prevalence of Diabetes and Associated Obesity in Pennsylvania Adults, 1995-2010. Preventing Chronic Disease, 11, Article ID: 13033. http://dx.doi.org/10.5888/pcd11.130330

[14] Mokdad, A.H., Bowman, B.A., Ford, E.S., Vinicor, F., Marks, J.S. and Koplan, J.P. (2001) The Continuing Epidemics of Obesity and Diabetes in the United States. JAMA, 286, 1195-1200. http://dx.doi.org/10.1001/jama.286.10.1195

[15] Venkataraman, R., Nanda, N.C., Baweja, G., Parikh, N. and Bhatia, V. (2004) Prevalence of Diabetes Mellitus and Related Conditions in Asian Indians Living in the United States. American Journal of Cardiology, 94, 977-980. http://dx.doi.org/10.1016/j.amjcard.2004.06.048

[16] Booth, F.W., Roberts, C.K. and Laye, M.J. (2012) Lack of Exercise Is a Major Cause of Chronic Diseases. Comprehensive Physiology, 2, 1143-1211.

[17] Colberg, S.R., et al. (2010) Exercise and Type 2 Diabetes: The American College of Sports Medicine and the American Diabetes Association: Joint Position Statement. Diabetes Care, 33, e147-e167. http://dx.doi.org/10.2337/dc10-9990

[18] dos Santos, A.L.T., Weiss, T., Duarte, C.K., de Azevedo, M.J. and Zelmanovitz, T. (2009) Análise crítica das recomendações da Associação Americana de Diabetes para doença cardiovascular no diabetes melito. Arquivos Brasileiros de Endocrinologia \& Metabologia, 53, 657-666. http://dx.doi.org/10.1590/S0004-27302009000500018

[19] Lindstrom, J., et al. (2006) Sustained Reduction in the Incidence of Type 2 Diabetes by Lifestyle Intervention: Follow-Up of the Finnish Diabetes Prevention Study. The Lancet, 368, 1673-1679. http://dx.doi.org/10.1016/S0140-6736(06)69701-8

[20] Nothlings, U., et al. (2008) Intake of Vegetables, Legumes, and Fruit, and Risk for All-Cause, Cardiovascular, and Cancer Mortality in a European Diabetic Population. Journal of Nutrition, 138, 775-781. 
[21] Martin-Timon, I., Sevillano-Collantes, C., Segura-Galindo, A. and del Cañizo-Gómez, F.J. (2014) Type 2 Diabetes and Cardiovascular Disease: Have All Risk Factors the Same Strength? World Journal of Diabetes, 5, 444-470. http://dx.doi.org/10.4239/wjd.v5.i4.444

[22] Chaturvedi, N., Stevens, L., Fuller, J.H. and The World Health Organization Multinational Study Group (1997) Which Features of Smoking Determine Mortality Risk in Former Cigarette Smokers with Diabetes? Diabetes Care, 20, 1266-1272. http://dx.doi.org/10.2337/diacare.20.8.1266

[23] Nilsson, P.M., et al. (2011) Trends in Blood Pressure Control in Patients with Type 2 Diabetes: Data from the Swedish National Diabetes Register (NDR). Blood Pressure, 20, 348-354. http://dx.doi.org/10.3109/08037051.2011.587288

[24] Cherry, D.K. and Woodwell, D.A. (2002) National Ambulatory Medical Care Survey: 2000 Summary. Advance Data, No. 328, 1-32.

[25] Meigs, J.B., Cupples, L.A. and Wilson, P.W. (2000) Parental Transmission of Type 2 Diabetes: The Framingham Offspring Study. Diabetes, 49, 2201-2207. http://dx.doi.org/10.2337/diabetes.49.12.2201

[26] Weijnen, C.F., Rich, S.S., Meigs, J.B., Krolewski, A.S. and Warram, J.H. (2002) Risk of Diabetes in Siblings of Index Cases with Type 2 Diabetes: Implications for Genetic Studies. Diabetic Medicine, 19, 41-50. http://dx.doi.org/10.1046/j.1464-5491.2002.00624.x

[27] Field, A.E., et al. (2001) Impact of Overweight on the Risk of Developing Common Chronic Diseases during a 10-Year Period. Archives of Internal Medicine, 161, 1581-1586. http://dx.doi.org/10.1001/archinte.161.13.1581

[28] Phillips, L.K. and Prins, J.B. (2008) The Link between Abdominal Obesity and the Metabolic Syndrome. Current Hypertension Reports, 10, 156-164. http://dx.doi.org/10.1007/s11906-008-0029-7

[29] Schulze, M.B., Heidemann, C., Schienkiewitz, A., Bergmann, M.M., Hoffmann, K. and Boeing, H. (2006) Comparison of Anthropometric Characteristics in Predicting the Incidence of Type 2 Diabetes in the EPIC-Potsdam Study. Diabetes Care, 29, 1921-1923. http://dx.doi.org/10.2337/dc06-0895

[30] Wang, Y., Rimm, E.B., Stampfer, M.J., Willett, W.C. and Hu, F.B. (2005) Comparison of Abdominal Adiposity and Overall Obesity in Predicting Risk of Type 2 Diabetes among Men. The American Journal of Clinical Nutrition, 81, 555-563. 